\title{
Comparison of miRNA expressions among benign, premalignant and malignant lesions of the larynx: could they be transformation biomarkers?
}

\author{
Fatma Ruya Tuncturk ${ }^{1,2^{*}}$, Ibrahim Akalin ${ }^{3,4}$, Lokman Uzun ${ }^{1}$ and Tulay Zenginkinet ${ }^{5}$
}

\begin{abstract}
Background: The malignancy potential of the laryngeal lesions are one of the major concerns of the surgeons about choosing the treatment options, forming surgical margins, deciding the follow-up periods. Finding a biomarker to overcome these concerns are ongoing challenges and recently microRNAs (miRNAs) are attributed as possible candidates since they can regulate gene expressions in the human genome. The objective of our study was to investigate their capability as a transformation biomarker for malignant laryngeal lesions.

Materials and methods: We investigated mature miRNA expressions in paraffin-embedded surgical specimens of human laryngeal tissues grouped as benign, premalignant or malignant ( $n=10$ in each). miRNA profiling was carried out by quantitative Real-Time polymerase chain reaction (RT-qPCR) and data were analyzed according to fold regulation.

Results: Our results demonstrated that 9 miRNAs were upregulated as the lesions become more malignant. Among them Hs_miR-183_5p, Hs_miR-155_5p, and Hs_miR-106b_3p expressions were significantly $4.16(p=0.032), 2.72(p=$ 0.028 ) and $3.01(p=0.022)$ fold upregulated respectively in premalignant lesions compared to the benign lesions. Moreover, their expressions were approximately 2.76 fold higher in the malignant group than in the premalignant group compared to the benign group. Besides them, significant $7.57(p=0.036), 4.45(p=0.045)$ and $5.98(p=0.023)$ fold upregulations of Hs_miR-21_5p, Hs_miR-218_3p, and Hs_miR-210_3p were noticed in the malignant group but not in the premalignant group when compared to the benign group, respectively.

(Continued on next page)
\end{abstract}

\footnotetext{
* Correspondence: dr.ruyatuncturk@gmail.com

It was presented as an oral presentation in Young Scientist's Forum 7th European Conference on Head and Neck Oncology (ECHNO). Also, this presentation was one of the best eight presentations in ECHNO2016. 'Department of Otolaryngology, Head and Neck Surgery, Istanbul Medeniyet University Faculty of Medicine, Istanbul, Turkey

${ }^{2}$ Dr. Behçet Uz Child Disease and Pediatric Surgery Training and Research Hospital Department of Otolaryngology-Head Neck Surgery, Ismet Kaptan Mh, Sezer Doğan Sok No:11, 35210, Konak/zmir, Turkey

Full list of author information is available at the end of the article
}

(c) The Author(s). 2021 Open Access This article is licensed under a Creative Commons Attribution 4.0 International License, which permits use, sharing, adaptation, distribution and reproduction in any medium or format, as long as you give appropriate credit to the original author(s) and the source, provide a link to the Creative Commons licence, and indicate if changes were made. The images or other third party material in this article are included in the article's Creative Commons licence, unless indicated otherwise in a credit line to the material. If material is not included in the article's Creative Commons licence and your intended use is not permitted by statutory regulation or exceeds the permitted use, you will need to obtain permission directly from the copyright holder. To view a copy of this licence, visit http://creativecommons.org/licenses/by/4.0/. The Creative Commons Public Domain Dedication waiver (http://creativecommons.org/publicdomain/zero/1.0/) applies to the data made available in this article, unless otherwise stated in a credit line to the data. 
(Continued from previous page)

Conclusion: MiRNAs might have important value to help the clinicians for their concerns about the malignancy potentials of the laryngeal lesions. Hs_miR-183_5p, Hs_miR-155_5p, and Hs_miR-106b_3p might be followed as transformation marker, whereas Hs_miR-21_5p, Hs_miR-218_3p, and Hs_miR-210_3p might be a biomarker prone to malignancy.

Keywords: miRNA, Larynx, Carcinoma, Leukoplakia, Hyperplasia, Biomarker

\section{Background}

Laryngeal carcinoma is one of the most common malignancies in the head and neck region with a good prognosis when in the early stages [1]. However, in advanced stages, responses are weak despite the diverse and novel treatment modalities [2]. The 5-year survival rate of patients with stage 1 laryngeal cancer can reach up to $90 \%$, whereas the 5-year survival rate of the patients with stage 4 laryngeal carcinoma does not even reach to $10 \%$ [2]. Traditionally, laryngeal carcinomas are staged according to 'TNM classification' and a 'histopathological grading system'. But, even they are same tumor type within the same tumor classification and at the same localization, the laryngeal tumors that are treated with the same modalities could represent different prognoses. Therefore, the malignancy potential of any laryngeal lesion is important to know to designate the medical or surgical treatment options. Nonetheless, underlying immunohistochemical, pathophysiological or genetic factors such as post-transcriptional regulators could interfere with a malignant transformation that is needed to be investigated.

MicroRNAs (miRNA) are endogenous, small, noncoding RNAs that are 21-24 nucleotides in length and known to regulate gene expression by silencing target transcripts via complement base-pairing in various pathways including embryogenesis, development, differentiation, and apoptosis [3]. miRNAs are also reported to regulate other pathological and physiological processes including cancer [4-6]. Since the protooncogenic and tumor-suppressive effects of miRNAs have been shown, miRNAs have also been investigated in head and neck cancers beside others [6]. Hu et al. have shown a significant correlation between miRNA expression and the factors affecting cancer stages and grades such as lymph node metastasis and distant site metastasis [7]. The relationships of miRNAs expressions with survival rates and prognosis have also been reported in terms of cigarette and/or alcohol consumption besides the demographic features. Though, recent studies have compared premalignant and malignant lesions in head and neck cancers, particularly in oral cavity tumors such as $\mathrm{Yu}$ et al. has stated miR-21, miR-106b and miR-375 as novel potential biomarkers [7-9]. Moreover, when compared to healthy controls Ayaz et al, has reported significant upregulation and downregulation of 17 (including miR-21) and 9 miRNAs in laryngeal squamous cell carcinoma, particularly [8]. The given studies held healthy subjects or specimens as the control group and reported significant results when compared to healthy controls. Those previously known miRNAs expressed in malignant laryngeal lesions was our rationale to investigate them within our study, since we aimed to elucidate whether there is/are particular miRNA(s) among them could be more prone to be a biomarker of transformation across the benign, premalignant, malignant laryngeal tumors when compared to the benign laryngeal lesions.

\section{Materials and methods}

Here, Hs_miR-21_5p,Hs_miR-106b_3p, Hs_miR-375_5p, $H s \_m i R-155 \_5 p, H s \_l e t 7 a \_5 p, H s \_m i R-210 \_3 p, H s \_m i R-$ 425_3p, Hs_miR-183_5p, and Hs_miR-218_3p expressions were investigated within paraffin-embedded specimens that were obtained from patients who underwent surgery because of laryngeal lesions between the years 2012 and 2015. After local ethical committee approval (2014/0196), informed consent was obtained from the patients. The samples were analyzed within 3 groups as benign (vocal cord polyps; $n=10$ ), premalignant (moderate-high-grade dysplasia; $n=10$ ) and malignant (squamous cell carcinoma; $n=10$ ). Patients who had previous cancer history or had been treated with radiochemotherapy were all excluded. One expert pathologist reviewed $5-\mu \mathrm{m}$ sections containing the lesions of interest from the FFPE samples. The sections were transferred to the genetics laboratory in suitable conditions.

\section{Isolation of miRNA-enriched total RNA and complementary DNA synthesis}

miRNAs were isolated from the paraffin-embedded tissues of the patients using the miRNeasy FFPE Kit (Qiagen) according to the manufacturer's protocol. Briefly, xylene and ethanol (\%96-100) were used to remove paraffin before total RNA isolation. Next, the pellet was treated with $10 \mu \mathrm{l}$ of proteinase $\mathrm{K}$. The fully deparaffinized and lysed laryngeal tumor supernatant was transferred to a new microcentrifuge tube and DNase I was added to eliminate the DNA content. Then, RNeasy MinElute Spin Column (Qiagen) and relevant buffers of the kit were used with subsequent centrifugation and 
flow-through steps at $8000 \mathrm{~g}$ for $15 \mathrm{~s}$. Finally, miRNAenriched total RNA was eluted with $14 \mu \mathrm{l}$ of RNase-free water.

$c$ DNAs were randomly primed from $5 \mu$ g of miRNAenriched total RNA with miScript II Reverse Transcription (Rt) Kit (Qiagen). Briefly, reverse transcription PCR was performed with $4 \mu \mathrm{l}$ of $5 \mathrm{x}$ miScript HiSpec Buffer, $2 \mu \mathrm{l}$ of 10x Nucleic Acid Mix, $1 \mu \mathrm{l}$ of miScript Reverse Transcriptase Mix, $8 \mu \mathrm{l}$ of RNase-free water and $5 \mu \mathrm{l}$ of template RNA, with a total of volume of $20 \mu \mathrm{l}$. The Rt reaction was incubated at $37^{\circ} \mathrm{C}$ for $60 \mathrm{~min}$ and $95^{\circ} \mathrm{C}$ for $5 \mathrm{~min}$. The cDNA was then diluted with $200 \mu \mathrm{l}$ of nuclease-free water for further use in real-time PCRs.

\section{Real-time PCR}

Nine miRNAs covering a variety of miRNA sequences were selected, and mature miRNA expression was determined via quantitative real-time polymerase chain reaction (RT-qPCR) with a QuantiTech SYBR Green PCR Kit (Qiagen) on the Rotor-Gene ${ }^{\circ} \mathrm{Q}$ (Qiagen, USA) instrument using the 2.1.0.9 software. RT-PCR was performed twice for each biological cDNA samples after optimization, including negative and non-template controls.

\section{Data analysis and statistics}

The threshold was manually determined as 0.025 in all reactions, and standards were calculated as follows: conc $=10^{\wedge}\left(-0.293^{*} \mathrm{CT}+7.516\right)$; and $\mathrm{CT}$ values were calculated as follows: $\mathrm{CT}=-3.410 * \log$ (conc) +25.632 , with an $R^{2}$ value of 0.9963 . The slope of the standard curve was determined to be -3.410 , and $R 2=0.99630$. CT values were exported from the RT-PCR instrument after normalization via the 'Dynamic Tube' and 'Slope Correction' options of the RT-PCR software used. For determining fold change, samples were normalized using housekeeping genes SNORD68, SNORD95 and MIRTC relevant for miRNA studies. Global mean normalization was used for $\mathrm{Ct}$ values and calculated concentrations were exported into the Excel spreadsheet, and the average value of duplicate $\mathrm{Ct}$ values was converted to quantities for analysis. The quality of expended mature miRNAs was checked via melt curve analyses using SYBR Green. Then, the $\mathrm{Ct}$ data were analyzed according to the fold-change $(2(-\Delta \Delta C T))$ method and converted into fold regulation values using the online miScript miRNA PCR Array Data
Analysis Tool (www.qiagen.com). $p$ values under 0.05 were considered statistically significant.

\section{Results}

Patient demographic data were shown in Table 1. In group 1, the mean age was $43.5 \pm 14.13$ (minimum age: 23 , maximum age: 64 ). In group 2 , the mean age was $60.3 \pm 8.71$ (minimum age: 50, maximum age: 77). In group 3, the mean age was $58 \pm 7.89$ (minimum age: 45 , maximum age: 70 ). Gender for all 30 patients was male.

Fold regulations of the miRNA expressions in premalignant, malignant laryngeal lesions compared to benign lesions were given in Table 2 and Fig. 1.

In the premalignant group Hs_miR-375_5p, Hs_miR183_5p, Hs_miR-155_5p, Hs_let-7a_5p, Hs_miR-21_5p and Hs_miR-106b_3p expressions were upregulated; however, in comparison to benign group, only the overexpression of $H s \_m i R-183 \_5 p, H s \_m i R-155 \_5 p$ and $\boldsymbol{H} \boldsymbol{s} \_\boldsymbol{m i R}-\mathbf{1 0 6} \boldsymbol{b} \_\mathbf{p} \boldsymbol{p}$ were statistically significant. $(p<0.05)$. The most upregulated miRNA was Hs_miR-183_5p, whereas Hs_miR-155_5p expression represented the lowest fold regulation (less than 2 folds).

$H s \_m i R-375 \_5 p, H s \_m i R-183 \_5 p, H s \_m i R-155 \_5 p$, Hs_let-7a_5p, Hs_miR-425_3p, Hs_miR-21_5p, Hs $m i R-218 \_3 p, H s \_m i R-210 \_3 p$ and $H s \_m i R-106 b \_3 p$ were all upregulated in the malignant group compared to benign group. However, in addition to significantly upregulated miRNAs in the premalignant group ( $H s_{-}$ miR-183_5p, Hs_miR-155_5p, Hs_miR-106b_3p), overexpressions of $\boldsymbol{H s} \_$miR-218_3p, Hs_miR-210_3p and $\boldsymbol{H} s_{-}$ miR-21_5p were also statistically significant. $(p<0.05)$. The most upregulated miRNA was Hs_miR-183_5p, whereas $H s \_m i R-218 \_3 p$ was the lowest.

In other words, Hs_miR-183_5p, Hs_miR-155_5p, and $H s \_m i R-106 b \_3 p$ expressions were statistically significant in both premalignant and malignant groups compared to the benign group, whereas $H s_{-} m i R-21 \_5 p, H s_{-}$ miR-218_3p, and Hs_miR-210_3p expressions were statistically significant only in the malignant group.

When the malignant group was compared with the premalignant group, all miRNAs were upregulated in the malignant group. The most upregulated miRNA was $H s \_m i R-$ 425_3p whereas Hs_miR-106b_3p was the lowest (Table 3).

Overall, after normalization with SNORD65 and SNORD98 all miRNAs that we studied here represented upregulation as the laryngeal samples were transformed to malignant (Fig. 2). Among them, significant

Table 1 Patient's demographic data. (SD: Standard deviation). M: male

\begin{tabular}{lllll}
\hline & Number of patient $(\mathbf{n})$ & Gender & Age range & mean age \pm SD \\
\hline Group 1 & 10 & male & $23-64$ & $43,5 \pm 14,13$ \\
Group 2 & 10 & male & $50-77$ & $60,3 \pm 8,71$ \\
Group 3 & 10 & male & $45-70$ & $58 \pm 7,89$ \\
\hline
\end{tabular}


Table 2 Fold regulations of the miRNA expressions in premalignant, malignant laryngeal lesions compared to benign lesions C.I. Confidence Interval

\begin{tabular}{|c|c|c|c|c|c|c|}
\hline \multirow[t]{3}{*}{ Genes } & \multicolumn{6}{|c|}{ Fold Regulations (compared to benign group) } \\
\hline & \multicolumn{3}{|c|}{ PREMALIGNANT GROUP } & \multicolumn{3}{|c|}{ MALIGNANT GROUP } \\
\hline & Fold Regulation & $p$-value & C.I. $95 \%$ & Fold Regulation & $p$-value & C.I. $95 \%$ \\
\hline Hs_miR-375_5p & 2.88 & 0.089235 & $(0.02,5.74)$ & 7,22 & 0.105618 & $(0.00001,15.57)$ \\
\hline Hs_miR-183_5p & 4.16 & 0.031872 & $(0.00,8.32)$ & 12.50 & 0.020141 & $(0.00001,26.86)$ \\
\hline Hs_miR-155_5p & 2.72 & 0.027845 & $(0.55,4.90)$ & 7.75 & 0.016086 & $(0.00001,15.73)$ \\
\hline Hs_let-7a_5p & 4.12 & 0.129245 & $(0.39,7.86)$ & 10.55 & 0.167083 & $(0.00001,22.11)$ \\
\hline Hs_miR-425_3p & 1.14 & 0.483030 & $(0.23,2.05)$ & 5.53 & 0.097976 & $(0.00001,11.12)$ \\
\hline Hs_miR-21_5p & 3.45 & 0.066857 & $(0.01,6.89)$ & 7.57 & 0.036338 & $(0.00001,16.88)$ \\
\hline Hs_miR-218_3p & 1.40 & 0.408852 & $(0.30,2.50)$ & 4.45 & 0.044747 & $(0.00001,10.54)$ \\
\hline Hs_miR-210_3p & 1.86 & 0.291543 & $(0.00001,4.03)$ & 5.98 & 0.023422 & $(0.00001,12.20)$ \\
\hline Hs_miR-106b_3p & 3.01 & 0.021868 & $(0.30,5.73)$ & 7.31 & 0.015054 & $(0.19,14.44)$ \\
\hline
\end{tabular}

upregulations of Hs_miR-183_5p, Hs_miR-155_5p and $H s \_m i R-106 b \_3 p$ were observed both in premalignant and malignant lesions whereas $H s_{-} \_m i R-218 \_3 p, H s \_m i R-$ 210_3p and Hs_miR-21_5p were only seen in the malignant lesions compared to benign lesions.

\section{Discussion}

The importance of miRNAs in gene regulation has emerged in recent years. After the first miRNA Human_Lethal-7_5p (Hs_let-7a_5p) was identified in Caenorhabditis elegans; to date, thousands of miRNAs have been discovered and many more remain unknown [10-12]. The numbers of miRNA studies conducted from an oncological perspective have increased steadily within the last decade and their role in malignant transformation is still a mystery [13-16]. Here, we investigated whether or not any miRNAs investigated here could be qualified as the transformation biomarkers within the laryngeal carcinoma progression.

$H s \_$miR-106b_3p is another miRNA that targets the 3'UTR of retinoblastoma (RB) gene [17] and

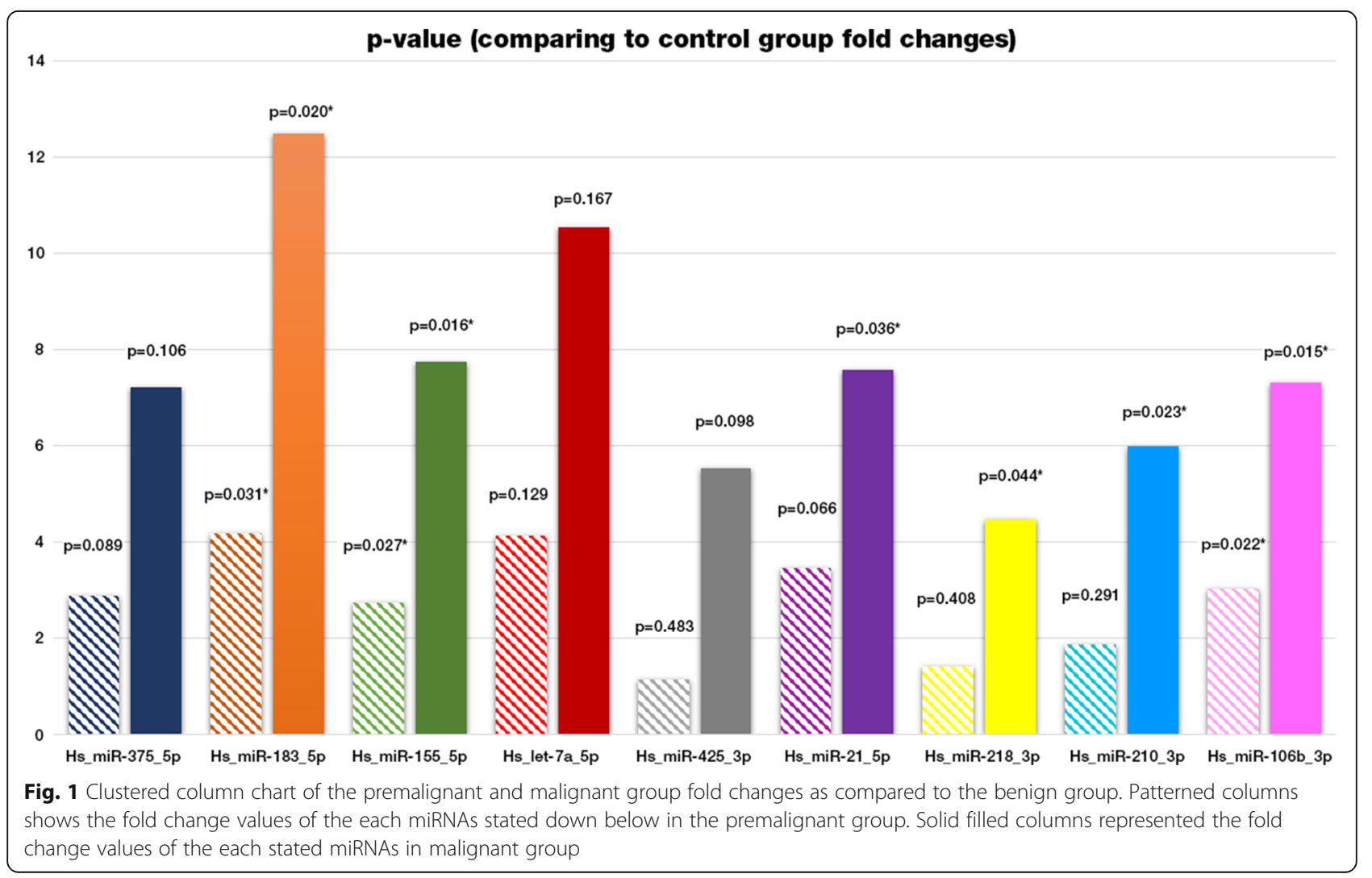


Table 3 Overexpressed microRNAs in malignant laryngeal lesions in comparison with the premalignant laryngeal lesions

\begin{tabular}{ll}
\hline Gene Symbol & Fold Regulation \\
\hline Hs_miR-375_5p & 25,062 \\
Hs_miR-183_5p & 30,032 \\
Hs_miR-155_5p & 28,491 \\
Hs_let-7a_5p & 25,589 \\
Hs_miR-425_3p & 48,517 \\
Hs_miR-21_5p & 21,939 \\
Hs_miR-218_3p & 31,766 \\
Hs_miR-210_3p & 32,165 \\
Hs_miR-106b_3p & 24,259 \\
\hline
\end{tabular}

upregulation of $R B$ largely inhibited by $m i R-106 b$ which further results in the induction of laryngeal carcinoma cells proliferation by deceased control of $R B$ on $\mathrm{G} 1 / \mathrm{S}$ transition of the cell cycle [17]. Though $\mathrm{Xu}$ et al. demonstrated a facilitated inhibition of cell proliferation and invasion due to the $H s \_m i R-106 b \_3 p$ downregulation [18], Sun et al. identified a positive correlation between the upregulation of $H s \_m i R-106 b \_3 p$ and lymph node metastasis, cancer stage in supraglottic laryngeal carcinoma [19]. In our study, compared to a benign group, we found 3.01 and 7.31 fold significantly increased $H s \_m i R-$ $106 b \_3 p$ expressions both in the premalignant and malignant groups, respectively (Table 2). However, when we compare the expressions in the malignant group with premalignant groups, $H s \_m i R-106 b \_3 p$ expression was not statistically significant. Hence, our results could suggest that $H s \_m i R-106 b \_3 p$ upregulation might be a transformation biomarker.

Similarly, Hs_miR-155_5p was also another miRNA that significant 2.72 and 7.75 fold increased expressions were noticed in the premalignant and malignant group compared to the benign group, respectively (Table 2). It has previously been studied in diverse malignancies, such as lung cancers, breast cancers and nasopharyngeal carcinomas [20, 21]. Among them, Shi et al. reported a positive correlation between $H s \_m i R-155 \_5 p$ expression and poor prognosis in oral cavity malignancies [20]. Moreover, Zhao et al. reported higher levels of $H s \_m i R-$ $155 \_5 p$ expression in higher grade T3 and T4 laryngeal tumors than T2 laryngeal tumors [22]. The latter was also consistent with ours since about three times higher expressions were observed in the malignant group compared to the premalignant group. Hence, the malignancy potential could be attributable to $H s \_m i R-155 \_5 p$ overexpression regardless of the other factors such as HPV related squamous cell carcinomas in the head and neck region [23]. In agreement with our study, results in the literature have primarily reported overexpression of $\mathrm{Hs}$ miR-155_5p, nevertheless, Abigail et al. suggested that viral infections could change gene expressions and argued that Hs_miR-155_5p expression needed to be analyzed in larger series [23].

$H s \_m i R-183 \_5 p$ on else has shown to play a role in cell differentiation, apoptosis, adhesion, and invasion. In colorectal, prostate and hepatic carcinomas, $H s \_m i R-$ 183 _ $5 p$ was upregulated, whereas in ovarian and breast cancers including osteosarcomas it was downregulated [24]. There are few studies on laryngeal carcinomas for Hs_miR-183_5p expressions. Among them, Maia et al. compared radioresistant and radiosensitive laryngeal carcinomas but their results were insignificant [25]. In our study, compared to its expression in the benign group, $H s \_m i R-183 \_5 p$ expression was increased by 4.16 and 12.50 fold in the premalignant and malignant group, respectively. Both groups generated statistically significant results (Table 2). However, Hs_miR-183_5p was known to target many enhancer transcription factors including

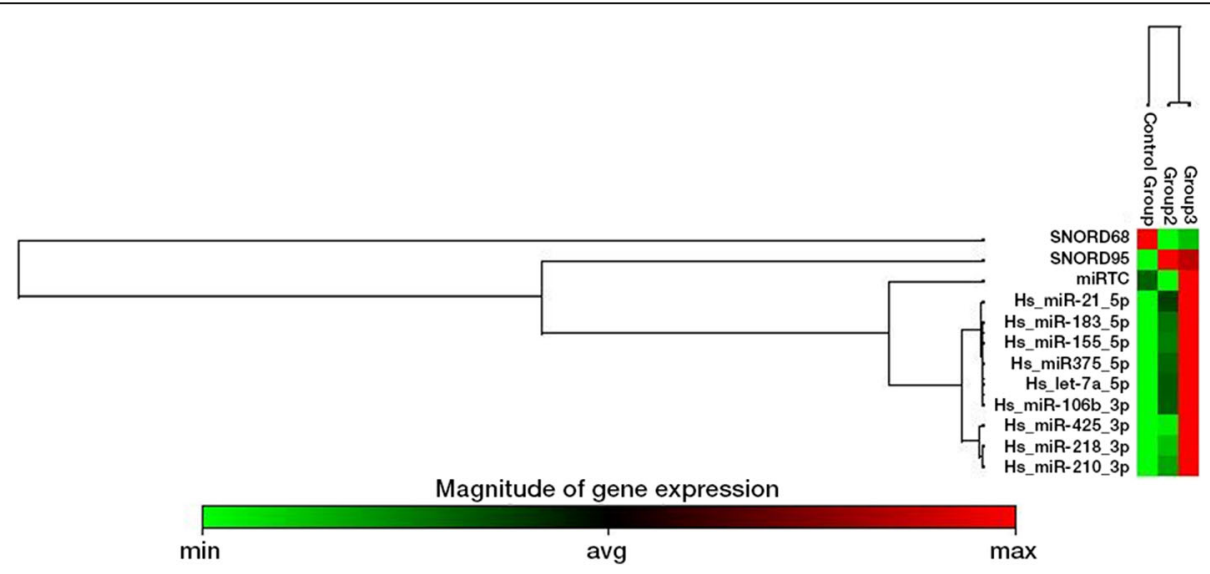

Fig. 2 Clustergram of miRNA expressions between the groups. Control group (benign group), group 2 (Premalignant group), group 3 (malignant group) are the columns and miRNA expressions are showed for each group. Green represented standard gene expression whereas red represented overexpressed miRNAs 
histone deacetylase 2 (HDAC2). Downregulation of the latter has found to induce apoptosis and inhibit cellular proliferation and migration of laryngeal squamous carcinoma cells [26]. Moreover, a reverse correlation was reported with the metastatic potential of lung cancer cells. In contrast to these, miR-183 has a potential oncogenic role through the regulation of tumor suppressor genes such as EGR1 and PTEN [27]. Hence, elevated expressions in the high-grade tumors might yield either as a compensatory mechanism to reduce the proliferation and migration through the repression of the transcription factors or to facilitate the tumor burden via the inhibition of the tumor suppressor genes. Whatever the reason why we have had a higher expression pattern in laryngeal carcinomas, the deregulation of this fundamental miRNA in its regulatory network may be significant imply on being the transformation biomarker for the laryngeal tumors.

Furthermore, $H s \_m i R-21 \_5 p$ upregulations were supposed to be oncogenic for different kinds of tumors [2836]. As a apoptosis regulating miRNA [37], Hs_miR-21_ $5 p$ would be a prognostic marker in head and neck tumors that is relevant to our results in which the $H s_{-}$ miR-21_5p was one of the three miRNAs that significantly upregulated solely in the malignant laryngeal tumors group (Table 2). Li et al. showed that in tongue squamous cell carcinoma, $H s \_m i R-21 \_5 p$ was a prognostic marker, and by inhibiting miR-21 with ASOs (antisense oligonucleotides), survival and growth of tumor cells were reduced, and apoptosis was induced [31]. On the other hand, Childs et al. found no correlation between any clinical parameters and Hs_miR-21_5p [32]. But, Avissar et al. reported a significant correlation between Hs_miR-21_5p expression and 5-year survival rates in the head and neck carcinomas [35]. Additionally, Lui et al. demonstrated that Hs_miR-21_5p was an oncomir which is overexpressed in laryngeal carcinomas compared to adjacent normal laryngeal tissue [38]. They reported a significant correlation between tumor stage, lymph node metastasis, tumor aggressiveness and survival [38]. In our study, compared to benign lesions, $H s_{-}$ miR-21_5p expression was 3.45 -fold and 7.57-fold increased in the premalignant and malignant group, respectively (Table 2). In the same way, Wei et al. obtained comparable results from a larger study representing $H s \_m i R-21 \_5 p$ overexpression in premalignant and malignant laryngeal tissue samples in comparison with benign laryngeal tissues [39]. Though $H s \_m i R-21$ $5 p$ overexpression was distinguishably significant only in the malignant group, hence, it might promote tumorigenesis by inhibiting apoptosis. We could not determine the exact reason but we have some potential explanations. First, we studied moderate-high-grade dysplasias as premalignant lesions, second due to pathological evaluation could be subjective and there was no certain consensus about grading of dysplasia. Third, Wei et al. has studied larger series than our that might have an impact.

The next miRNA which was significantly overexpressed only in the metastatic group was the $H s \_m i R-$ $218 \_3 p$ (Table 2). The latter was known to act as a tumor suppressor in several malignancies, such as renal cell carcinomas, lung cancers, and pancreatic carcinomas $[40,41]$. Though limited studies were in the literature for laryngeal carcinomas, of the few that exist, Fukumoto et al. showed downregulation of Hs_miR-218_3p expression in laryngeal carcinomas. They identified that the silencing of LOLX2 (lysyl oxidase-like 2), a target gene of $H s \_m i R-218 \_3 p$, inhibited migration and invasion in tumor cells [42]. Additionally, Takashi et al. reported it to regulate the migration and invasion of tumor cells via local adhesion pathways. They suggested that determining the mechanism of $H s \_m i R-218 \_3 p$ could clarify the mechanism of local recurrence and distant metastasis [43]. Besides, Abigail et al. compared HPV-negative and HPV-positive head and neck cancers and showed significant downregulation of $m i R-218$ in the HPV-positive group [23]. In another study on cervical cancers, similar results were obtained for HPV-positive cervical cancers. In the same study, it was also shown that the downregulation of $H s \_m i R-218 \_3 p$ by the E6 oncogene could cause overexpression of $L A M B 3$, which is a target of Hs_miR$218 \_3 p$ [23]. In opposite to these, Shi et al. highlighted the reversal of the growth inhibition in human gastric cancer cells caused by $m i R-218$ regulated TFF1. Likewise, overexpression of $H s \_m i R-218 \_3 p$ in the malignant group might negatively regulate TFF1 in an Erk1/2dependent manner and promote malignancy as suggested [44]. However, we did not have the opportunity to analyse HPV status. In the literature, the majority of studies show downregulation of $H s \_m i R-218 \_3 p$ in laryngeal carcinomas. Thus, we believe that unknown factors such as viral infections can affect the results, which should be investigated in larger series.

The discrepancies on Hs_miR-210_3p whether or not it is a tumor suppressor or an oncomir is still ongoing for many tumor types. Apart from that, Gee et al. indicated a correlation between the upregulation of Hs_miR-210_3p and poor prognosis in head and neck tumors by helping the vitality of tumor cells in hypoxic conditions [30]. Also it was associated with radiotherapy resistance in lung cancers in the same study [30]. In our study, compared to its expression in the benign group, $H s \_m i R-210 \_3 p$ expression was significantly 7.31 fold increased in the malignant group (Table 2). However, only the overexpression of $H s \_m i R-210 \_3 p$ in the malignant group was statistically significant (Table 2). Due to the challenging 
results in the literature more studies with larger series are needed to be investigated.

On the other hand, Hs_miR-375_5p has shown to be downregulated in malignancies including head and neck tumors $[45,46]$. Overexpression of $H s \_m i R-375 \_5 p$ reported to reduce cellular proliferation and migration in liver cells while stimulating both apoptosis and G1 arrest during the cell cycle [45]. Also, it was shown that $m i R$-375 overexpression could affect patient survival via reducing invasion by targeting YAP1, JAK2 and phosphoinositidedependent protein kinase-1(PDK1) [46]. Furthermore, Luo et al. enriched Harris's suggestion and showed how $\mathrm{Hs}_{-}$ miR-375_5p overexpression inhibited cell proliferation, migration, invasion and resulted in increased apoptosis via IGF1R expression [47]. Since the latter was a target of $m i R-375$, increasing levels of $m i R-375$ expression could provide a significant reduction in IGF1R levels and its downstream signaling molecule $A K T$ in laryngeal carcinoma cells [47]. Quaamari et al. also presented $P D K-1$ as the target of Hs_miR-375_5p that contributed to AKT activation [48]. Despite all, Hu et al. identified a negative association between the alcohol use and Hs_miR-375_5p expression and indicated that the ratio of $m i R-21 / m i R-375$ had a $94 \%$ sensitivity and $94 \%$ specificity for distinguishing normal tissue from laryngeal carcinoma tissue [45].

Apart from that, Yu et al. discovered overexpression of $H s \_m i R-106 b \_3 p$ and Hs_miR-21_5p, while downregulation of Hs_miR-375_5p expression in laryngeal carcinoma tissue compared to adjacent normal tissue [9]. Furthermore, the expression of Hs_miR-106b_3p and $H s \_m i R-21 \_5 p$ expressions in poor and moderately differentiated laryngeal carcinomas were more upregulated than that in the benign and dysplastic laryngeal tissues [9]. Despite the results for $H s_{-} m i R-106 b_{-} 3 p$ and $H s_{-}$ $m i R-21 \_5 p$ were consistent with our data the downregulation of Hs_miR-375_5p expression particularly in advanced stages than in earlier stages was inconsistent [9]. Even though, its expression in the premalignant and malignant group were respectively 2.88 and 7.22 fold increased compared to the benign group, these values in our study were not statistically significant (Table 2 ).

In addition to this, Hs_miR-425_3p served as an oncomir and stimulated cell proliferation and inhibited apoptosis [49]. Furthermore, Li et al. found a correlation between Hs_miR-425_3p upregulation and lymph node metastasis in laryngeal carcinomas [50]. Notwithstanding that, in our study, Hs_miR-425_3p expressions were insignificantly increased (Table 2). In the same way, $\mathrm{Hs}_{-}$ let-7a_5p expression was insignificantly 4.12 -fold and 10.54-fold upregulated in premalignant and malignant laryngeal tissues when compared to benign laryngeal samples (Table 2). However, Long et al. has shown that let-7a expression was significantly downregulated in laryngeal squamous cell carcinomas compared to adjacent normal tissues and was significantly further decreased in non-differentiated carcinoma tissues compared with moderately and well-differentiated ones [13]. In contrast to them, in our study let-7a expression was insignificantly further upregulated as the tissues became more malignant. (Table 2, Fig. 2) Long et al. also identified 11 carcinoma samples $(23 \%)$ demonstrating unchanged or even slightly elevated expression levels of let-7a compared with adjacent normal tissues [13]. They subsequently hypothesized that let-7a could have different impacts on different individuals or that let-7a may not take part in the pathogenesis of all laryngeal carcinomas [13]. In the light of this information, we believe that further investigations with larger series are needed particularly for those miRNAs who have insignificant results such as Hs_miR-375_5p, Hs_miR-425_3p, and Hs_let$7 a \_5 p$.

\section{Conclusion}

Our study is one of the first to compare the expression levels of several different miRNAs between benign, premalignant and malignant laryngeal lesions with a relatively larger series upon the literature. They indicated that $H s_{-}$ $m i R-21 \_5 p, H s \_m i R-218 \_3 p$, and $H s \_m i R-210 \_3 p$ can be a potential biomarker for malignant laryngeal carcinomas. Furthermore, Hs_miR-183_5p, Hs_miR-155_5p, and Hs miR-106b_3p, each upregulated both in premalignant and malignant groups compared to benign hyperplasia, might have a great value to help physicians to determine the malignancy potential of the laryngeal lesions as the transformation biomarkers upon prognosis.

\section{Acknowledgments}

The study is supported by the Research Fund of the University. Project Numbers: T-UZM-2015-668 and TSG-2013-333.

\section{Authors' contributions}

IA and LU planned the study. LU coordinated the study. LU and FRT worked on the patient files. FRT found suitable specimens for the study and informed the patients. TZ took sections from the specimens and transferred the material in suitable conditions to the genetics laboratory. IA worked molecularly on specimens from isolation to expressions of miRNAs in the genetic laboratory. FRT, IA, LU analyzed the results and all contributed to the MS. The author(s) read and approved the final manuscript.

\section{Funding}

The research is supported by the Research Fund of the institution. Project Numbers: T-UZM-2015-668 and TSG-2013-333. The fee of miRNeasy Mini KIt (50), miScript II RT Kit (12), miScript Primer Assay (200 rxn), miScript SYBR Green PCR Kit (400rxn) was covered by the funding.

\section{Availability of data and materials}

All data generated or analyzed during this study are included in this published article.

Ethics approval and consent to participate

The study protocol has been approved by the institute's committee of human research and ethics (Protocol number: 2014/0196). 


\section{Competing interests}

The authors declare that they have no competing interests.

\section{Author details}

'Department of Otolaryngology, Head and Neck Surgery, Istanbul Medeniyet University Faculty of Medicine, Istanbul, Turkey. ${ }^{2}$ Dr. Behçet Uz Child Disease and Pediatric Surgery Training and Research Hospital Department of Otolaryngology-Head Neck Surgery, İsmet Kaptan Mh, Sezer Doğan Sok No:11, 35210, Konak/Izmir, Turkey. ${ }^{3}$ Department of Medical Genetics, Istanbul Medeniyet University Faculty of Medicine, Istanbul, Turkey. ${ }^{4}$ Current Address: Maltepe University Faculty of Medicine Department of Medical Genetics, Istanbul, Turkey. ${ }^{5}$ Department of Medical Pathology, Istanbul Medeniyet University Faculty of Medicine, Istanbul, Turkey.

\section{Received: 29 June 2019 Accepted: 7 February 2021}

\section{Published online: 27 February 2021}

\section{References}

1. Clayman GL. Neoplasms of the head and neck. In: Bast Jr RC, Kufe DW, Polock RE, Weichselbaum RR, Holland JF, Frei E, editors. Cancer medicine. 5th ed. New York: BC Decker Inc.; 2000. section 27.

2. Rosai J. Respiratory tract. In: Rosai and Ackerman's surgical pathology, vol. 1. 9th ed. China: Elsevier; 2004. p. 335-59.

3. Fabbri M. miRNAs as molecular biomarkers of cancer. Expert Rev Mol Diagn. 2010;10:435-44 PubMed PMID: 20465498.

4. Aslan E, Akbas E, Yilmaz S, Karaoglu AS, Telli U, Yildirim S, et al. Ear atresia: Is there a role of apoptosis-regulating miRNAs? vol. 5; 2018. p. 238-45.

5. Ding L, Liu J, Shen HX, Pan LP, Liu QD, Zhang HD, et al. Analysis of plasma microRNA expression profiles in male textile workers with noise-induced hearing loss. Hear Res. 2016;333:275-82. https://doi.org/10.1016/..heares.201 5.08.003.

6. Lee YS, Dutta A. MicroRNAs in cancer. Annu Rev Pathol. 2009;4:199-227. https://doi.org/10.1146/annurev.pathol.4.110807.092222.

7. Hu Y, Liu H. MicroRNA-10a-5p and microRNA-34c-5p in laryngeal epithelial premalignant lesions: differential expression and clinicopathological correlation. Eur Arch Otorhinolaryngol. 2015;272:391-9. https://doi.org/10.1 007/s00405-014-3299-5.

8. Ayaz L, Görür A, Yaroğlu HY, Ozcan C, Tamer L. Differential expression of microRNAs in plasma of patients with laryngeal squamous cell carcinoma: potential early-detection markers for laryngeal squamous cell carcinoma. Cancer Res Clin Oncol. 2013;139:1499-506. https://doi.org/10.1007/s00432013-1469-2.

9. Yu X, Wu Y, Liu Y, Deng H, Shen Z, Xiao B, et al. miR-21, miR-106b and miR375 as novel potential biomarkers for laryngeal squamous cell carcinoma. Curr Pharm Biotechnol. 2014;15:503-8.

10. Tunalı NE, Tiryakioğlu NO. Kanserde MikroRNA'ların Rolü. Türkiye Klinikleri 」 Med Sci. 2010;30:1690-700.

11. Rosenfeld N, Aharonov R, Meiri E, Rosenwald S, Spector Y, Zepeniuk M, et al. MicroRNAs accurately identify cancer tissue origin. Nat Biotechnol. 2008;26: 462-9. https://doi.org/10.1038/nbt1392.

12. Kozomara A, Griffiths-Jones S. miRBase: integrating microRNA annotation and deep-sequencing data. Nucleic Acids Res. 2011;39(Database issue): D152-7. https://doi.org/10.1093/nar/gkq1027 Epub 2010 Oct 30.

13. Long XB, Sun GB, Hu S, Liang GT, Wang N, Zhang $X H$, et al. Let-7a microRNA functions as a potential tumor suppressor in human laryngeal cancer. Oncol Rep. 2009;22:1189-95.

14. Harris T, Jimenez L, Kawachi N, Fan JB, Chen J, Belbin T. Low-level expression of miR-375 correlates with poor outcome and metastasis while altering the invasive properties of head and neck squamous cell carcinomas. Am J Pathol. 2012;180:917-28. https://doi.org/10.1016/j.ajpath.2 011.12.004.

15. Marcucci G, Mrózek K, Radmacher MD, Garzon R, Bloomfield CD. The prognostic and functional role of microRNAs in acute myeloid leukemia. Blood. 2011:117:1121-9. https://doi.org/10.1182/blood-2010-09-191312

16. Chen J, Zhang D, Zhang W, Tang Y, Yan W, Guo L, et al. Clear cell renal cell carcinoma associated microRNA expression signatures identified by integrated bioinformatics analysis. J Transl Med. 2013;11:169. https://doi. org/10.1186/1479-5876-11-169.

17. Cai K, Wang Y, Bao X. MiR-106b promotes cell proliferation via targeting RB in laryngeal carcinoma. J Exp Clin Cancer Res. 2011;30:73. https://doi.org/1 0.1186/1756-9966-30-73
18. Xu Y, Wang K, Gao W, Zhang C, Huang F, Wen S, et al. MicroRNA-106b regulates the tumor suppressor RUNX3 in laryngeal carcinoma cells. FEBS Lett. 2013;587:3166-74. https://doi.org/10.1016/j.febslet.2013.05.069.

19. Sun $X$, Song $Y$, Tai X, Liu B, Ji W. MicroRNA expression and its detection in human supraglottic laryngeal squamous cell carcinoma. Biomed Rep. 2013; 1:743-6.

20. Shi LJ, Zhang CY, Zhou ZT, Ma JY, Liu Y, Bao ZX, et al. MicroRNA-155 in oral squamous cell carcinoma: Overexpression, localization, and prognostic potential. Head Neck. 2015;37:970-6. https://doi.org/10.1002/hed.23700.

21. Jiang $\mathrm{S}$, Zhang HW, Lu MH, He XH, Li Y, Gu H, et al. MicroRNA-155 functions as an OncomiR in breast cancer by targeting the suppressor of cytokine signaling 1 gene. Cancer Res. 2010;70:3119-27. https://doi.org/10.1158/00085472.CAN-09-4250.

22. Zhao XD, Zhang W, Liang HJ, Ji WY. Overexpression of miR -155 promotes proliferation and invasion of human laryngeal squamous cell carcinoma via targeting SOCS1 and STAT3. PLoS One. 2013;8:e56395. https://doi.org/10.13 71/journal.pone.0056395.

23. Wald Al, Hoskins EE, Wells SI, Ferris RL, Khan SA. Alteration of microRNA profiles in squamous cell carcinoma of the head and neck cell lines by human papillomavirus. Head Neck. 2011;33:504-12. https://doi.org/10.1002/hed.21475.

24. Chen J, Gu L, Ni J, Hu P, Hu K, Shi YL. MiR-183 regulates ITGB1P expression and promotes invasion of endometrial stromal cells. Biomed Res Int. 2015; 2015:340218. https://doi.org/10.1155/2015/340218.

25. Maia D, de Carvalho AC, Horst MA, Carvalho AL, Scapulatempo-Neto C, Vettore AL. Expression of miR-296-5p as predictive marker for radiotherapy resistance in early-stage laryngeal carcinoma. J Transl Med. 2015;13:262. https://doi.org/10.1186/s12967-015-0621-y.

26. Yuan LL, Lou WH, Sang JZ, Li SL, Li WC, Zhonghua BL, Xue ZZ. Downregulation of histone deacetylase 2 induces cell apoptosis and inhibits cell proliferation and migration of laryngeal squamous cell carcinoma cells. Zhonghua Bing Li Xue Za Zhi. 2012;41:396-9. https://doi.org/10.3760/cma.j. issn.0529-5807.2012.06.008.

27. Sarver AL, Li L, Subramanian S. MicroRNA miR-183 functions as an oncogene by targeting the transcription factor EGR1 and promoting tumor cell migration. Cancer Res. 2010;70(23):9570-80. https://doi.org/10.1158/ 0008-5472. CAN-10-2074.

28. Liu J, Lei DP, Jin T, Zhao XN, Li G, Pan XL. Altered expression of miR-21 and PTEN in human laryngeal and hypopharyngeal squamous cell carcinomas. Asian Pac J Cancer Prev. 2011;12:2653-7.

29. Ma GJ, Gu RM, Zhu M, Wen X, Li JT, Zhang YY, et al. Plasma post-operative miR-21 expression in the prognosis of gastric cancers. Asian Pac J Cancer Prev. 2013;14:7551-4.

30. Gee HE, Ivan C, Calin GA, Ivan M. HypoxamiRs and cancer: from biology to targeted therapy. Antioxid Redox Signal. 2014;21:1220-38. https://doi.org/1 0.1089 /ars.2013.5639

31. Li J, Huang H, Sun L, Yang M, Pan C, Chen W, et al. MiR-21 indicates poor prognosis in tongue squamous cell carcinomas as an apoptosis inhibitor. Clin Cancer Res. 2009;15:3998-4008. https://doi.org/10.1158/1078-0432.CCR-08-3053.

32. Childs G, Fazzari M, Kung G, Kawachi N, Brandwein-Gensler M, McLemore M, et al. Low-level expression of microRNAs let-7d and miR-205 are prognostic markers of head and neck squamous cell carcinoma. Am J Pathol. 2009;174: 736-45. https://doi.org/10.2353/ajpath.2009.080731.

33. Meng F, Henson R, Wehbe-Janek H, Ghoshal K, Jacob ST, Patel T. MicroRNA21 regulates expression of the PTEN tumor suppressor gene in human hepatocellular cancer. Gastroenterology. 2007:133:647-58.

34. Gee HE, Camps C, Buffa FM, Patiar S, Winter SC, Betts G, et al. hsa-mir-210 is a marker of tumor hypoxia and a prognostic factor in head and neck cancer. Cancer. 2010;116:2148-58. https://doi.org/10.1002/cncr.25009.

35. Avissar M, McClean MD, Kelsey KT, Marsit CJ. MicroRNA expression in head and neck cancer associates with alcohol consumption and survival. Carcinogenesis. 2009;30:2059-63.

36. Jung HM, Phillips BL, Patel RS, Cohen DM, Jakymiw A, Kong WW. Keratinization-associated miR-7 and miR-21 regulate tumor suppressor reversion-inducing cysteine-rich protein with kazal motifs (RECK) in oral cancer. J Biol Chem. 2012;287:29261-72. https://doi.org/10.1074/jbc.M112.366518.

37. Aslan E, Akbas E, Yilmaz S, Karaoglu AS, Telli U, Yildirim S, et al. Ear atresia: Is there a role of apoptosis-regulating miRNAs? North Clin Istanb. 2018:5(3): 238-45. https://doi.org/10.14744/nci.2017.26680

38. Liu M, Wu H, Liu T, Li Y, Wang F, Wan H, et al. Regulation of the cell cycle gene, BTG2, by miR-21 in human laryngeal carcinoma. Cell Res. 2009;19: 828-37. https://doi.org/10.1038/cr.2009.72. 
39. Wei L, Mao M, Liu H. Droplet digital PCR, and qRT-PCR to detect circulating miR-21 in laryngeal squamous cell carcinoma and pre-malignant laryngeal lesions. Acta Otolaryngol. 2016 Sep;136(9):923-32. https://doi.org/10.3109/ 00016489.2016 .1165862$.

40. Uesugi A, Kozaki K, Tsuruta T, Furuta M, Morita K, Imoto I, et al. The tumor suppressive microRNA miR-218 targets the mTOR component Rictor and inhibits AKT phosphorylation in oral cancer. Cancer Res. 2011;71:5765-78.

41. Alajez NM, Lenarduzzi M, Ito E, Hui AB, Shi W, Bruce J, et al. MiR-218 suppresses nasopharyngeal cancer progression through downregulation of survivin and the SLIT2-ROBO1 pathway. Cancer Res. 2011;71:2381-91.

42. Fukumoto I, Kikkawa N, Matsushita R, Kato M, Kurozumi A, Nishikawa R, et al. Tumor-suppressive microRNAs (miR-26a/b, miR-29a/b/c and miR-218) concertedly suppressed metastasis-promoting LOXL2 in head and neck squamous cell carcinoma. J Hum Genet. 2016;61:109-18. https://doi.org/10.1 038/jhg.2015.120.

43. Kinoshita T, Hanazawa T, Nohata N, Kikkawa N, Enokida H, Yoshino H, et al. Tumor suppressive microRNA-218 inhibits cancer cell migration and invasion through targeting laminin-332 in head and neck squamous cel carcinoma. Oncotarget. 2012;3:1386-400.

44. Shi Y, Chen GB, Huang QW, Chen X, Liu JJ, Xu W, et al. miR218-5p regulates the proliferation of gastric cancer cells by targeting TFF1 in an Erk1/2dependent manner. Biochim Biophys Acta. 2015;1852(5):970-9. https://doi. org/10.1016/j.bbadis.2015.01.016.

45. Hu A, Huang JJ, Xu WH, Jin XJ, Li JP, Tang YJ, et al. miR-21 and miR-375 microRNAs as candidate diagnostic biomarkers in squamous cell carcinoma of the larynx: association with patient survival. Am J Transl Res. 2014;6:60413.

46. Jamali Z, Asl Aminabadi N, Attaran R, Pournagiazar F, Ghertasi Oskouei S, Ahmadpour F. MicroRNAs as prognostic molecular signatures in human head and neck squamous cell carcinoma: a systematic review and metaanalysis. Oral Oncol. 2015;51:321-31. https://doi.org/10.1016/j.oraloncology.2 015.01.008.

47. Luo J, Wu J, Li Z, Qin H, Wang B, Wong TS, et al. miR-375 suppresses IGF1R expression and contributes to inhibition of cell progression in laryngeal squamous cell carcinoma. Biomed Res Int. 2014;2014:374598. https://doi. org/10.1155/2014/374598.

48. El Ouaamari A, Baroukh N, Martens GA, Lebrun P, Pipeleers D, van Obberghen E. miR-375 targets 3'-phosphoinositide-dependent protein kinase-1 and regulates glucose-induced biological responses in pancreatic beta-cells. Diabetes. 2008;57:2708-17. https://doi.org/10.2337/db07-1614.

49. Liu L, Zhao Z, Zhou W, Fan X, Zhan Q, Song Y. Enhanced Expression of miR425 Promotes Esophageal Squamous Cell Carcinoma Tumorigenesis by Targeting SMAD2. J Genet Genomics. 2015;42:601-11. https://doi.org/10.101 6/j.jgg.2015.09.010

50. Li L, Zhang ZM, Liu Y, Wei MH, Xue LY, Zou SM, et al. DNA microarraysbased microRNA expression profiles derived from formalin-fixed paraffinembedded tissue blocks of squammous cell carcinoma of larynx. Zhonghua Bing Li Xue Za Zhi. 2010;39:391-5.

\section{Publisher's Note}

Springer Nature remains neutral with regard to jurisdictional claims in published maps and institutional affiliations.

Ready to submit your research? Choose BMC and benefit from:
- fast, convenient online submission
- thorough peer review by experienced researchers in your field
- rapid publication on acceptance
- support for research data, including large and complex data types
- gold Open Access which fosters wider collaboration and increased citations
- maximum visibility for your research: over 100M website views per year
At BMC, research is always in progress.
Learn more biomedcentral.com/submissions

